\title{
Steroid cell ovarian tumor: A case report of an unusual condition
}

\author{
Paban Kumar Sharma', Sujan Joshi ${ }^{2}$ \\ Dept of Ob/Gyn'/ Pathology 2 \\ MIDAT Clinic, Lagankhel, Lalitpur
}

\begin{abstract}
A young girl presented with a solid pelvic tumor, was found to be steroid cell tumor of ovary, is described here because of its rarity and its association with unexplained anemia which was spontaneously corrected after the tumor removal.

Ovarian steroid cell tumor is known to account for approximately $0.1 \%$ of all ovarian neoplasms and is unfortunately seen to exerts malignant potentials although its association with multiple different endocrine or paraneoplastic changes are the main issues with affection to women of young as well.
\end{abstract}

Key words: Steroid cell tumor, lipoid tumor.

\section{Introduction}

Ovarian steroid cell tumours account for approximately $0.1 \%$ of all ovarian neoplasms. ${ }^{1}$ These are rare tumours for which there is interest, not for their malignant potential, but for their association with multiple different endocrine or paraneoplastic changes.

The histogenesis of steroid cell tumor of ovary is still controversial. They are thought to arise from ovarian stroma, hilus or adrenal cortical rests and secrete steroid hormones. ${ }^{1}$

This case is reported for its rarity and its unusual presentation of not having any clinical signs and symptoms typical of a steroid hormone-secreting tumor apart from size $(>7 \mathrm{~cm}$ ) besides being distinguishable from leutinised granulosa cell tumour, thecoma, clear cell carcinoma, metastatic renal cell carcinoma and lipid rich sertoli cell tumour that form differential diagnosis.

\section{Case}

A 27 year unmarried normally menstruating student from Kathmandu was admitted with a diagnosis of mass in lower abdomen in MIDAT Clinc for laparotomy. She gave history of pain in lower back on and off for the last 10 year, for which she had been receiving analgesic medication intermittently until one year ago; when she developed generalized weakness and bruising of skin. Diagnosis of anemia was made at that time with the record of hemoglobin as $6 \mathrm{gm}$ percentage and PCV $18 \%$, peripheral smears that showed hypochromic picture with anisocytosis. Leukocyte with total and differential counts including the platelet was within normal limit along with normal reticulocyte count. Two unit of blood were transfused, yet the hemoglobin level did not rise to a normal level despite, additional iron supplementation.

On further investigation, liver function test and blood biochemistry (serum urea, creatinine, blood sugar, electrolytes) were also found to be within normal level. A sonography done after eight months (2008.7.6) showed $10.4 \times 7 \times 7.3 \mathrm{~cm}$ fairly well defined solid mass in the pelvic cavity just superior to the fundus of the uterus. Second opinion on pelvic ultrasound was taken a week later from another radiologist, which showed similar well-defined solid mass, $9.8 \times 6.4 \mathrm{~cm}$ in dimension but oval in shape, with a pedicle, giving apparently an impression of pedunculated fibroid. Uterus was found to be normal in size. The mass did not appear to be ovarian in origin as it was located anterior to the uterus moderately compressing the urinary bladder. CT scan

Correspondence

Dr. Paban Kumar Sharma. MD Ob/Gyn

paban.sharma@gmail.com 
too, pointed out a solid well-defined heterogeneous mass $(9 \times 7.6 \times 7.5 \mathrm{~cm})$, showing moderate enhancement of the mass on post contrast study. There was an enlarged lymph node in aortic bifurcation area without any free fluid in the peritoneal cavity. The differential diagnoses suggested were lymphoma, gastrointestinal stromal tumor (GIST) and ovarian mass. Ca 125, beta hCG and alfa feto protein all were normal limit.

All the pre-operative investigations were within normal limit except for hemoglobin level, which was $9 \mathrm{gm}$ percentage even then. Laparotomy was done 2008.7.29. Per operative findings showed about $100 \mathrm{ml}$ of clear fluid in the pelvis. Uterus, other ovary, tubes and other viscera were normal looking. No lymph node was palpable. There was a solid tumor in left ovary, size $9 \mathrm{x}$ $8 \mathrm{~cm}$, as quoted in USG/CT, with intact capsule, devoid of any adhesion or any surface deposits (fig 1). Right adenectomy was done along with omental biopsy. Capsule of the tumor was white exposing yellow solid lobulated areas on cut section inside a septae separating the different lobules (fig 2). Microscopically, cytology was negative for malignant cells; omentum was normal looking giving histological impression as Steroid (Lipoid) cell tumor (fig 3).

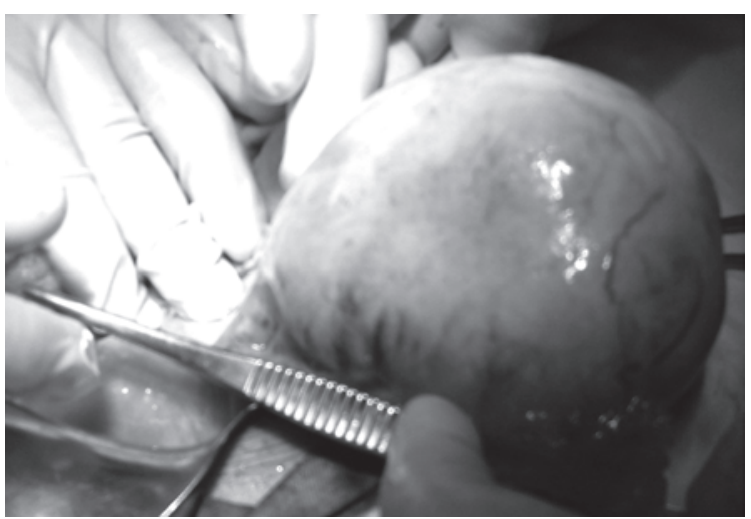

fig 1. ovarian cyst

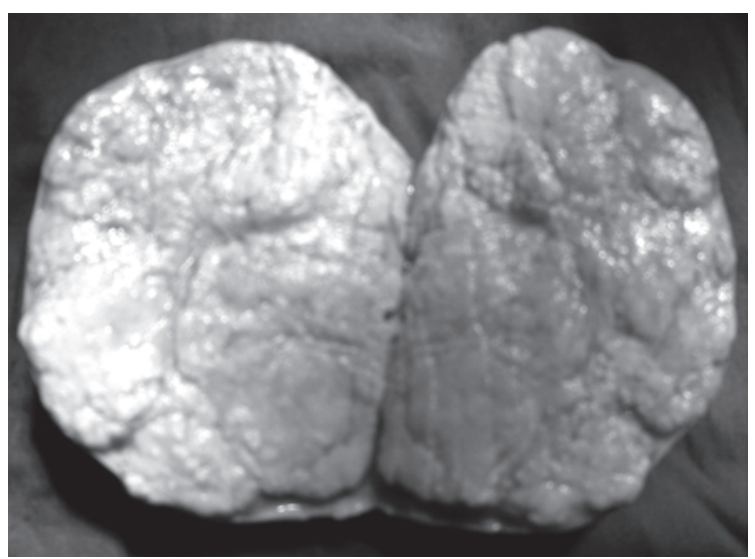

fig 2. cut section
Postoperative period was uneventful with good recovery. During the follow up in the past four months of surgery, there were two episodes of menorrhagia in subsequent months but the hemoglobin level was maintained at $\geq 10$ gm percentage with progesterone and iron.

\section{Comment}

Until recently, "lipid cell tumor" or "lipoid cell tumor" were believed to contain lipid and were named so accordingly. Lately, it came to knowledge that $25 \%$ of these tumors were found to contain little or no lipid in; thus Hayes and Scully ${ }^{1}$ in 1979 introduced new term "steroid cell tumor" to describe this rare group of tumours. This term justifies the morphological appearance of these tumors as well as provides insights into their clinical manifestations. They are subclassified according to their cells of origin.

\section{Subclassification}

1. Stromal luteoma

2. Leydig cell tumor

a. Hilus cell type

b. Leydig cell tumor, non-hilar type

3. Steroid cell tumor, not otherwise specified (NOS)

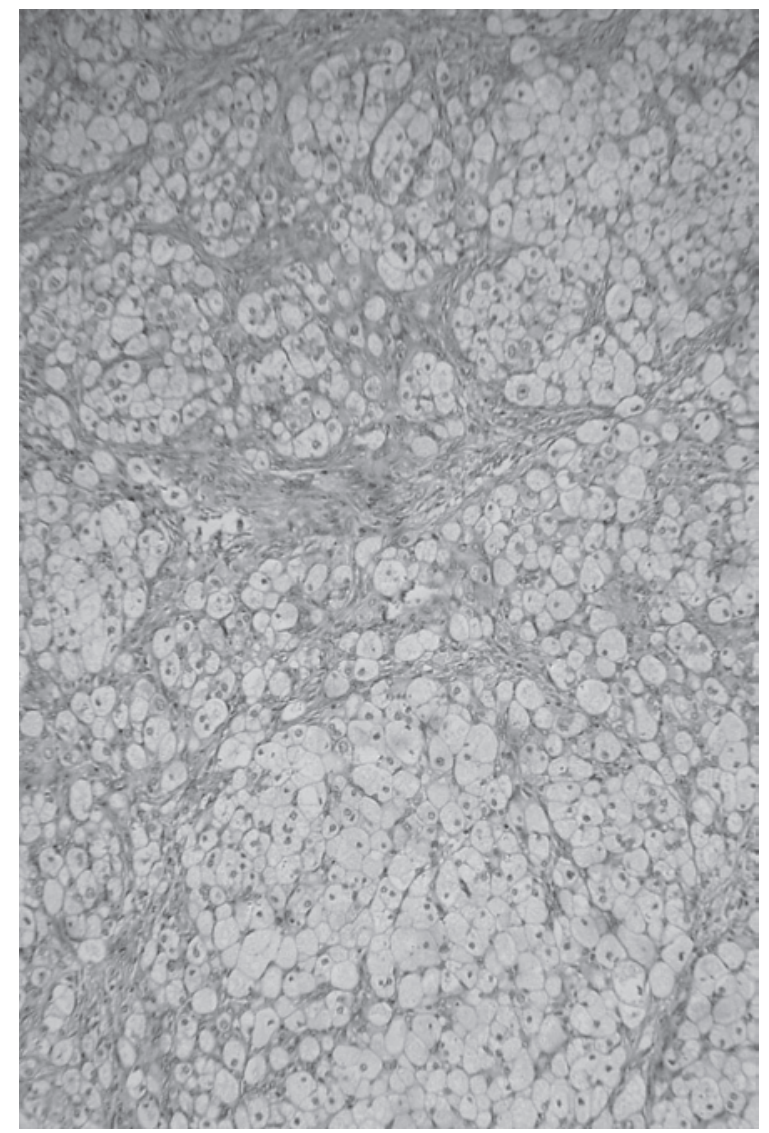

fig 3. histopathology 
Steroid cell tumours that cannot be diagnosed specifically as stromal luteomas or Leydig cell tumor subtypes are classified as steroid cell tumours, not otherwise specified (NOS). ${ }^{1}$ They occur at a younger age, occasionally before puberty (average age - 43 years) and represent about $60 \%$ of all steroid cell tumours. ${ }^{1-4}$ In contrast to benign nature of both the stromal luteomas and Leydig cell tumours, 25 to $43 \%$ of steroid cell tumours, NOS are malignant. ${ }^{1,5}$ A rare case of malignancy has been reported in a 8 year old girl. ${ }^{3}$

The histological criteria for malignancy are grade 2 or 3 nuclear atypia, tumour diameter $(>7 \mathrm{~cm})$, mitotic rate $(>$ 2/hpf), necrosis and haemorrhage. Capsular penentration and vascular invasion also point to malignancy, although metastasis is the only definite sign of malignancy. ${ }^{1}$

Steroid cell tumours, NOS are associated with androgenic changes in $50 \%$ of the cases, estrogenic in 6 to $23 \%$ cases while few cases have shown presentational changes ${ }^{1,2}$. About 10 to $15 \%$ of them are asymptomatic, being incidentally detected during pelvic examination or at surgery. ${ }^{6}$

Virilization, an unusual clinical presentations of NOS association and with hypothyroidism and secondary hyperlipidemia has been reported. ${ }^{7}$ This may include, Cushing's syndrome (6 to $10 \%$ cases), estrogenic manifestations or isosexual pseudoprecocious puberty. ${ }^{1,2,8}$ A renin secreting tumour associated with secondary polycythaemia has also been reported. ${ }^{9}$ Other rare examples have been associated with erythrocytosis, hypercalcaemia, ascitis and aldosterone secretion. ${ }^{1,10}$

In conclusion, a steroid cell tumor of the ovary may present as solid ovarian tumor and in young women too.

\section{References}

1. Hayes MC, Scully RE. Ovarian steroid cell tumors (not otherwise specified). A clinic pathological analysis of 63 cases. Am J Surg Pathol 1987; 11:835-845.

2. Adeyemi SD, Grange AO, Giwa-Osagie OF, Elesha SO. Adrenal rest tumor of the ovary associated with isosexual precocious pseudopuberty and cushingoid features. Eur J Pediatr 1986;145:236.

3. Naik VS, Jashnani KD, Kandalkar BM, Oak SN. Steroid (lipid) cell tumour of the ovary in an eight year old girl. Bhj.org/journal/2005_july/html/ case_steroid.

4. Campbell PE, Danks DM. Pseudoprecocity in an infant due to a luteoma of the ovary. Arch Dis Child 1963;38:518-23.

5. Taylor HB, Norris HJ. Lipid cell tumours of the ovary. Cancer 1967;20:1953-62.

6. Hartmann LC, Young RH, Podratz KC. Ovarian sex cord-stroma tumors. In: Hoskins WJ, Perez CA, Young RC, eds. Principles and Practice of Gynecologic Oncology. $3^{\text {rd }}$ edn. Lippincott Williams and Wilkins, 2000:1059

7. Tsai HJ, Chen SC, Wei HY, Chen GD. Hypothyroidism and Hyperlipidemia with a Virilizing Ovarian steroid cell tumor, Not Otherwise Specified.

8. Donovan BJ, Otis CN, Powell JL, Cathcart HK. Cushing's syndrome secondary to malignant lipoid cell tumour of the ovary. Gynecol Oncol 1993;50:249-53.

9. Stephen MR, Lindop GBM. A renin secreting ovarian steroid cell tumour associated with secondary polycythaemia. J Clin Pathol 1998; 51:75-82.

10. Kulkarni JN, Mistry RC, Kamat MR, Chinoy R, Lotlikar RG. Case report of autonomous aldosterone-secreting ovarian tumour. Gynaecologic Pathology 1990; 37:284-9. 